\title{
O espertar de Dormente: feminismo, humor e teatro na nova versión do clásico de Raquel Castro
}

The awakening of Dormente: feminism, humour and drama in the new version of the literary classic by Raquel Castro

\author{
Alicia Anta iD \\ Centro Ramón Piñeiro para a Investigación en Humanidades, España \\ alianta@usal.es
}

Recibido: 14/10/2021; Aceptado: 21/11/2021

\section{Resumo}

O presente traballo supón unha pequena achega ao estudo de Dormente, a obra teatral de literatura infantil e xuvenil de Raquel Castro publicada neste ano 2021. A través da súa lectura, dedúcese o propósito da autora por despatriarcalizar o conto de $A$ bela dormente. A tal fin, Castro dota ao renovado discurso de novos contidos e novas formas que distan do clásico, e sobre os que se porá o foco de atención atendendo a varios eixos: trazos feministas, humor e comicidade e estilo.

Palabras chave: Literatura infantil e xuvenil; Dormente; Raquel Castro; $A$ bela dormente.

\begin{abstract}
This paper aims to make a contribution to the study of the YA and Children's play Dormente by Raquel Castro, published in 2021. By reading through her work, it becomes clear the author attempts to "depatriarchalise" the tale of Sleeping Beauty. To achieve this, Castro provides the reader with new content using innovative techniques that differ from the classic tale, thus updating the prevailing narrative. In this review, we will focus on these changes by examining certain key points: feminist features, humour and comedy, and style.
\end{abstract}

Keywords: Children's and Young Adult Literature; Dormente; Raquel Castro; Sleeping Beauty.

\section{INTRODUCIÓN}

Unha mala fada que le o xornal? Unha aprendiz de meiga que vai ao insti? Unha vella obsesionada co bingo? Certamente, estes son algúns dos personaxes que desfilan por Dormente, a nova obra teatral que Raquel Castro (Alxén, Salvaterra de Miño, 1971) ven de publicar no pasado mes de xullo. A obra, dirixida a un público xuvenil, enmárcase dentro da colección “árbore” da Editorial Galaxia, ao 
igual que outros títulos teatrais da autora, coma As terapias da doutora Ledicia (2012) ou A formiga fóra do carreiro (2018), así como a novela Bestiario doméstico (2017).

\section{A VELLA DORMENTE}

No caso de Dormente, esta podería definirse como unha recreación da máis que coñecida versión dos irmáns Grimm do conto de fadas A bela dormente, perfectamente resumido por Ramírez (2014, p. 207), como a historia dunha malpocada meiga que, anoxada por non ser convidada ao bautizo da pequena princesa, bota un esconxuro sobre ela, agoirando que se picará co fuso dunha roca cando sexa moza, motivo polo cal todo o reino e máis ela caerán nun profundo sono durante un século enteiro até a chegada dun príncipe que logrará espertala ao darlle un bico de amor, vivindo ámbolos dous, tras o normal desposorio, nunha eterna felicidade.

\section{A NOVA DORMENTE}

Dende a lectura das primeiras liñas, é doado decatarse de que a obra non pretende a representación teatral dun conto ao uso. A autora mestura de maneira maxistral elementos da realidade actual (detectives, xornais, institutos, redes sociais...) con axentes propios dos contos de fadas (rei, raíña, princesa, príncipe, cocheiro, castelo, meigas, sapos, esconxuros...). Así pois, o estudo e análise do relato infanto-xuvenil de Castro -que se esmiuzará en adiante e que como se verá, pouco ten que ver co orixinal-, xustifícase pola súa contribución na ruptura dunha historia e duns valores tradicionais enraizados no imaxinario colectivo e que a autora reconstrúe por medio da inserción de novos personaxes, novas tramas e un sorprendente xiro do final que permiten, en definitiva, dotar ao relato dunha nova perspectiva ao redor dun diálogo actual para unha reinterpretación total do seu sentido: Dende hai un ano, a princesa Bela segue a durmir e ninguén no reino sabe o porqué. o Rei, que ten as súas sospeitas, decide contratar os servizos de XASA, a axencia de detectives privados de Xerlo e Amara para que atopen o causante do letargo da princesa e lle poidan por remedio. Todos os indicios sinalan a Malévola, unha meiga vingativa coa que o Rei mantivera unha relación antes de casar coa raíña. Esta, resentida, botara o devandito esconxuro sobre a futura filla do rei. Porén, non todo é o que parece. No transcurso da obra, vaise descubrindo que, en realidade, Dormente finxe o seu propio sono para non ter que casares con algún príncipe, que é a vontade de seus pais. Os detectives, coaccionados por Dormente, deciden axudala logrando reunir os personaxes no cuarto da rapaza e facendo ver que todos, en menor ou maior medida, son causantes do estado de somnolencia da princesa. A obra remata cando Toniño -fillo de Malévola e ao que fixeron pasar por príncipe-, tenta darlle un bico a Bela para espertala, mais Branca, a súa mellor amiga, interponse para ser ela que llo dea. Tras o beixo correspondido, Bela "acorda" e así é como se descobre que ambas amigas, en realidade, están namoradas. Esta nova trama supón un exemplo máis "de las reescrituras que proponen nuevos roles para la mujer, [donde] han quedado claramente trastocados los arquetipos de las princesas [...] así como el papel que desempeñan en la obra los protagonistas (ya no necesariamente héroes) masculinos" (Roig, B. A, 2010, p. 51). 


\section{TRAZOS FEMINISTAS}

\section{Liberdade afectivo-sexual da muller}

A orientación sexual de Dormente é clave no intento de Castro por despatriarcalizar o conto de A Bela Dormente, e por extensión, o resto de contos clásicos cuxos discursos adoutrinadores son asimilados dende a nenez. 0 feito de que a princesa protagonista sexa lesbiana ou bisexual sáese dos padróns da heterosexualidade e heteronormatividade dos que sempre se fixeron eco os contos de fadas. Así ocorre tamén noutras obras anteriores de literatura infantil e xuvenil de temática LGBTI como Titiritesa (2007), de Xerardo Quintiá, onde as princesas Titiritesa e Wendolina se namoran (Ferreira Boo, 2012, p. 54). No tocante aos estereotipos das personaxes femininas, Ramírez (2014, p. 207) sinala que estas "son adornadas, caracterizadas por la bondad, la virginidad, la capacidad para ser madre, la belleza y la pasividad", unhas características que, pola contra, non presenta Dormente.

Retomando o tema da súa orientación sexual, cómpre dicir, que trala sorpresa inicial que provoca para o resto dos personaxes, o bico entrambas dúas amigas, finalmente é ben recibido, e así se aprecia nesta intervención do Rei: "REI: e que mais ten, príncipe ou princesa. 0 importante é que Bela espertou" (Castro, 2021, p. 166) ${ }^{1}$. Así pois, a mensaxe transmitida é que o benestar e a felicidade da moza é a prioridade.

\section{Sororidade}

Do mesmo xeito, a obra pon en alza valores feministas coma o da sororidade, que se fai especialmente patente na escena 2 do segundo acto, no monólogo que Branca dirixe a unha Bela ausente, e que conforma, ao mesmo tempo, unha reivindicación da súa emancipación, e por extensión, a da muller:

BRANCA: Vou fuxir, vou fuxir do castelo e non volver nunca máis e ti, se foses lista, habías vir comigo. [...] Esperta, esperta dunha vez e fuxe comigo. [...] Eu quero ver mundo. Non quero casar, amiga, non quero casar. Eu sei que quedaches durmida á mantenta por non ter que escoller marido, mais esa non é a maneira. Hai que fuxir, hai que fuxir! Ven canda min, esperta e ven canda min, que eu te vou axudar [...]. (p. 73)

Así, Branca rompe con certos estereotipos asociados ás personaxes femininas, que:

mediante encumbramientos de la femineidad, como máximo valor en la mujer, la reducen a ser figura simbólica, con una función social estrechamente delimitada. Las razones confluyen en estar al servicio de la mantención de la estructura de la sociedad patriarcal. (Ramírez, 2014, p. 208)

\section{Prevención da violencia sexual}

Son moitos os personaxes que insisten en que Toniño, fillo de Malévola e amigo de Dormente, se converta no "príncipe" que lle haxa de dar un bico nos beizos para espertala. Con todo, Toniño négase a facelo sen o seu consentimento en varias ocasións: "TONIÑO: De ningunha maneira! Eu non vou bicar a princesa, sen o seu consentimento" (p. 134); "Si, claro que me gusta e iso que ten que ver? Eu non vou bicala sen o seu consentimento" (p. 136); "Moi fermosa, mais iso non significa 
que deba bicala sen o seu consentimento" (p. 153); "Que non a vou bicar, por favor, non insistan" (p. 153). É probable que a autora se sirva deste tipo de intervencións para lembrar a importancia dos dereitos sexuais das mulleres e contribuír así, nun sentido amplo e dende a lectura, coa prevención dos abusos e agresións sexuais ás mulleres.

\section{SOBRE OS PERSONAXES: HUMOR E COMICIDADE}

Podería definirse a obra de Castro coma unha comedia? Pode que a transcendencia da trama e do seu fondo non o permitan, mais é incuestionábel que o humorismo e a comicidade están presentes dende as primeiras páxinas, algo que se debe, en parte, á mestura de elementos da realidade e da ficción da que xorden escenarios únicos.

\section{Tipificación de personaxes}

Xerlo e Amara conforman o prototípico dúo de detectives propio das novelas negras ou policiais, onde un deles -neste caso Xerlo-, é pampo, galbán e mexericas, mentres que o outro -neste caso Amara-, amósase perspicaz, tenaz e ousada. Esta combinación dá como resultado unha morea de escenas e diálogos divertidos, ben entre eles, ben xunto con outros personaxes. Sirva como exemplo o diálogo que manteñen os detectives co Rei ao pouco de se coñecer:

AMARA: E a quen temos nós o pracer de coñecer?

REI: Son o rei.

XERLO: O Rei?

AMARA: Que Rei?

REI: O Rei, que rei vou ser, o Rei.

XERLO: E non ten nome?

REI: Teño moitos, mais todo o mundo se puxo de acordo en chamarme Rei ou "Súa maxestade".

AMARA: A súa?

REI: Non, a súa.

XERLO: A miña?

REI: (Irritado.) A de todos vostedes! (pp. 22-23)

\section{Desestereotipación de personaxes}

Se ben Xerlo e Amara parecen responder a personaxes-tipo, segundo se comentaba antes, no caso de Malévola, malia ser a priori a meiga antagonista, rómpense certos estereotipos asociados ás bruxas, o que fai que o lector-espectador vexa a Malévola non coma unha figura que encarne a malignidade, senón coma unha personaxe cómica e graciosa; esa "bruja desmitificada mediante la comicidad con su rol trastocado y que en lugar de dar miedo da risa en obras juveniles e infantiles de tono humorístico y desenfadado [...] (Ferreira, 2017, p. 49). Malévola lee o xornal, toma o té con pastas, os seus esconxuros non fan efecto e, ás veces, a súa variña quédase sen batería. De feito, nunha das súas intervencións deixa claro que non é unha meiga tradicional: "MALÉVOLA: Non ho! Onde vai que non teño gato, a min iso de que unha bruxa sempre teña que ir cun gato, paréceme unha parvada. Paso de estereotipos" (p. 133). 


\section{Caricaturización de personaxes}

Por outra banda, personaxes coma o Rei e a Raíña préstanse especialmente á caricaturización, ben sexa mediante indicacións escénicas ("Entra o Rei, ven limpando os mocos" (p. 61)), ben mediante algunhas intervencións da meiga ("MALÉVOLA: Eu ía ser a raíña, mais el, de súpeto, preferiu a actual raíña, unha pataca sen estilo ao meu lado" (p. 52); “[...] Que mellor vinganza pode haber que o xoubas ese do rei, teña que casar a súa filla co meu fillo [...]” (p. 135)).

\section{Personaxes chave}

Pero se hai un personaxe que non deixa indiferente ao lector, é a personaxe da vella: esa anciá xorda que vive na torre, dona do fuso co que Dormente se picara, e que finalmente acabara cambiando por un bingo. Tal é a súa obsesión por este xogo, que nas tres escenas onde aparece (escenas 5 e 6 do segundo acto e escena 4 do cuarto acto) sempre o leva consigo, remexendo as bolas, repartindo cartóns entre os personaxes e o público e cantando bingo cando lle peta. A actuación da vella, que vai berrando os números e que en todo momento se amosa allea ao que acontece ao seu redor, dota á obra dese toque propio do Teatro do Absurdo, un "teatro que carece de toda lógica racional, que se caracteriza por la devaluación del lenguaje y la falta de comunicación en la medida que no tratan de argumentar el absurdo de la existencia, sino de presentarlo tal como es" (Guillén, 2018, p. 7). Deste xeito, a obra regálanos escenas tan divertidas coma inverosímiles:

VELLA: Noventa. Nove, cero!

REI: (Entrando.) Bingo!

VELLA: O señor cantou bingo, parabéns! Gañou vostede... (Remexe na súa cesta.) gañou vostede unha tixola. (Dálle unha tixola).

RAÍÑA: E para que quere o Rei unha tixola, se non sabe nin fritir un ovo?

VELLA: Pois xa vai sendo hora que aprenda a fritir un ovo, que ser unha súa miña maxestade non é escusa para non entrar na cociña. [...]

XERLO: Mira para a vella, que parecía parva.

AMARA: Parva non, Xerlo, parecía xorda coma tí. (pp. 115-116)

Por outra parte, a interacción deste personaxe co público volve a obra máis dinámica e entretida ao implicar a participación activa do espectador:

Sobe ao escenario a persoa á que lle tocou o bingo, animada polos actores e actrices. [...] Convídano/a a bailar e cantar todos xuntos unha coreografía, dirixida pola VELLA, que os vai situando e pedíndolles que a imiten. [...] Pechamos o pano, se o estimado público non quere unirse á festa! (p. 172)

Asemade, esta vella tamén é a encargada, tal e como se le nas indicacións escénicas, de cambiar o decorado entre acto e acto ao ritmo de I want to break free.

\section{ESTILO, LINGUAXE E REMINISCENCIAS LITERARIAS}

Como non podía ser doutro xeito, a obra caracterízase pola inclusión dos elementos e convencionalismos teatrais, onde a autora non perde de vista a dimensión espectacular e a súa hipotética posta en escena. As indicacións escénicas, que ofrecen informacións relevantes acerca 
dos personaxes e do attrezzo, son as xustas e necesarias para que a obra non perda o ritmo no cambio entre acto e acto. Nelas, a autora non presume de amplos decorados nin se detén en descricións extensas ou grandilocuentes: unha aposta que, probablemente, busque centrar toda a atención do lector-espectador na trama e na mensaxe que se quere transmitir.

A obra, dividida en catro actos e un preacto, desenvólvese nunha xornada que ten lugar en tres escenarios: a oficina de detectives, a casa de Malévola e as dependencias do palacio real; porén, e malia ter coñecemento do tempo e espazo interno, non se amosan pistas sobre o externo. Se ben a autora opta por obviar o nome do reino e do lugar onde transcorre a trama (sexa vila ou cidade), hai presenza de suficientes referencias espazo-temporais que remiten á Galicia actual ${ }^{2}$.

Pola súa quenda, os parlamentos dos actantes responden á ficcionalización dun intercambio oral, coloquial, espontáneo, non planificado, con continuas réplicas e contraréplicas. Así, son frecuentes no discurso algúns dos fenómenos propios da oralidade recollidos en Jiménez Moreno (2005) que se detallan na seguinte táboa:

Táboa 1. Relación de fenómenos propios da oralidade e da linguaxe coloquial, e exemplos extraídos de Dormente, de Raquel Castro.

\begin{tabular}{|c|c|}
\hline Acurtamentos & $\begin{array}{l}\text { "MALÉVOLA: Eu tamén vou, que xa teño ganas de ver ao meu ex..." } \\
\text { (p. 137). }\end{array}$ \\
\hline Repeticións & $\begin{array}{l}\text { "BRANCA: Pasas de min? Pasa, pasa [...]" (p. 72). } \\
\text { "MALÉVOLA: Non pode ser! Non pode ser! [...]" (p. 121). }\end{array}$ \\
\hline Pleonasmos & "BRANCA: Eu ben sei por qué fas a durmida" (p. 72). \\
\hline Interxeccións & "XERLO: Ai, ai, ai! Que mala é vostede!" (p. 112). \\
\hline Diminutivos & $\begin{array}{l}\text { “XERLO: Non entendo nadiña!” (p. 110) } \\
\text { “MALÉVOLA: [...] Non sabedes o traballiño que dan os adolescentes } \\
\text { cando están espertos" (p. 143). } \\
\text { “RAÍ̃̃̃A: Ai, filliña miña!" (p. 163). }\end{array}$ \\
\hline Frase feita & "XERLO: Xa hai que ter mala baba!” (p. 31). \\
\hline Comparacións & “AMARA: Xorda coma unha tapia [...]” (p. 31). \\
\hline $\begin{array}{l}\text { Emprego } \\
\text { ironía }\end{array}$ & "AMARA: Moi orixinais, sí señor, son vostedes moi orixinais" (p. 33). \\
\hline
\end{tabular}

Por outro lado, é obrigado sinalar a extraordinaria calidade literaria que desprende a obra teatral e que se manifesta, entre outras, nas reminiscencias literarias evocadas ${ }^{3}$ que a continuación se sinalan:

- Hamlet, de William Shakespeare: Un fragmento do soliloquio de Dormente -presente na escena 1 no cuarto acto-, suscita un dilema ("DORMENTE: [...] Espertar, non espertar, espertar, non espertar..." (p. 139)) que evoca ese famoso "ser ou non ser" de Hamlet. 
- Brancaneves e os sete ananiños: Hai un momento concreto da obra onde se descobre que Branca, a amiga e namorada de Bela, é, en realidade, Brancaneves. Sucede no seu monólogo dirixido a Dormente, que ten lugar na escena 2 do segundo acto:

BRANCA: [...] Eu teño máis problemas ca ti, que aínda onte oín como a miña madrasta lle dicía a meu pai que quería meterme nun internado de sete ananos que hai no medio do monte. Oíches? Un internado: un anano ensina a bordar, outro a coser, outro a limpar a vaixela, outro a fregar, outro a pasar o ferro, outro a facer a comida e outro a zurcir as medias. (p. 73)

- Alicia no país das marabillas, de Lewis Carroll: As intervencións da Raíña -personaxe que representa unha muller dura, decidida, vingativa e ás veces lunática-, lembran, en non poucas ocasións, á personaxe da Raíña de corazóns, do famoso relato de Lewis Carroll. Menciónense como exemplo as seguintes: "[...] Xa hai tempo que ando con gana de matar a alguén" (p. 90); "Se ma dá a min [a tixola], espétolla na cabeza" (p. 116); "Voute matar" (p. 143); “Que lles corten a cabeza!!!” (p. 163).

- Sherlock Holmes, de Arthur Conan Doyle: Algunhas intervencións de Amara e Xerlo ${ }^{4}$ emulan os diálogos de Sherlock Holmes e Watson, protagonistas das coñecidas novelas detectivescas de Arthur Conan Doyle. É o caso de: "AMARA: Elemental, querido Xerlo, senón non viría por aquí" (p. 29).

\section{CONCLUSIÓN}

Dormente conforma, nun sentido amplo, unha obra de teatro de literatura infantil e xuvenil froito da deconstrución das formas e valores establecidos nos contos clásicos. Na mesma, Castro consegue botar abaixo o discurso patriarcal do coñecido conto de $A$ bela dormente, onde a autora desbota a trama orixinal e cámbiaa por unha versión renovada, feminista e acorde aos nosos tempos, onde a caracterización dos personaxes e os seus diálogos xogan un papel fundamental, non só para derrubar estereotipos (patriarcais e outros) senón tamén para dotar á obra dun humor branco, cun ton cómico e desenfadado. 0 estilo desta peza teatral, dende as indicacións escénicas até as intervencións dos actantes, caracterízase pola brevidade, dinamismo e unha linguaxe coloquial; un estilo que, ademais, deixa ver entre liñas elementos reminiscentes de clásicos da literatura universal coma Hamlet, Sherlock Holmes ou Alicia no pais das marabillas, entre outros.

En definitiva, Dormente é un dos exemplos máis recentes do panorama da reescritura da Literatura Infantil e Xuvenil galega que, dende a década dos setenta, se atopa en auxe, de acordo coas liñas establecidas por Rodari en Grammatica della fantasia, onde a intertextualidade, o humor e a desmitificación dos referentes compartidos ocupan un lugar preferente e desempeñan papeis fundamentais dentro desta corrente, algo que xa advertiran investigadoras como Ferreira Boo (2012).

\section{Referencias bibliográficas}

Autores/Raquel Castro. (2021, 13 de outubro). Editorial Galaxia. https://editorialgalaxia.gal/autor/raquel -castro/

Castro, R. (2021). Dormente. Editorial Galaxia. 
Ferreira Boo, C. (2012). La reescritura de brujas y princesas en la literatura infantil y juvenil gallega del siglo XXI. AILIJ (Anuario de Investigación en Literatura Infantil y Juvenil), 10, 47-56. https://revistas.webs.u vigo.es/index.php/AILIJ/article/view/886

Ferreira Boo, C. (2017). El personaje en el cuento maravilloso: la subversión de arquetipos femeninos de brujas, princesas y hadas. AILIJ (Anuario de Investigación en Literatura Infantil y Juvenil), 15, 41-56. ht tps://revistas.webs.uvigo.es/index.php/AILIJ/article/view/994

Guillén Sánchez, M. T. (2018). El Teatro del Absurdo: un reflejo existencialista del mundo contemporáneo [Traballo de Fin de Grao]. Universitat Jaume I, Comunitat Valenciana. http://hdl.handle.net/10234/1 $\underline{77789}$

Jiménez Moreno, J. C. (2005). Aproximaciones y breve análisis sistemático de la sintaxis coloquial. Interlingüística, 16(2), 631-639. https://dialnet.unirioja.es/descarga/articulo/2514252.pdf

Ramírez, N. (2014). La bella durmiente: análisis de algunas versiones tradicionales y sus reescrituras. Revista IIPSI, 17(2), 203-213. https://doi.org/10.15381/rinvp.v17i2.11267

Roig, B.A., Soto, I., e Neira, M. (2010). Reescrituras do conto popular (2000-2009). Edicións Xerais.

Notas

1 De aquí en adiante, e co fin de evitar a redundancia, as citas extraídas de Dormente (Castro, 2021) sinalaranse só co número da páxina ou páxinas ás que corresponden.

2 É o caso das referencias á Panorama e ao Combo dominicano, orquestras galegas de sona que gozan de ampla popularidade na actualidade: “VELLA: [...] Sí que imos facer boas festas este ano. Como mínimo traemos a Panorama ou o Combo dominicano!!” (pp. 151-152).

3 As intertextualidades preséntanse seguindo o criterio de orde cronolóxica de publicación.

4 Cómpre facer alusión á similitude fonética que se dá entre os antropónimos Xerlo e Sherlock.

Cómo citar: Anta, A. (2021). 0 espertar de Dormente: feminismo, humor e teatro na nova versión do clásico de Raquel Castro. Boletín Galego de Literatura, 59, “Notas”, 1-8. DOI http://dx.doi.org/10.15304/bg $\underline{1.59 .8011}$ 